\title{
Differentiation-Dependent Glycosylation of Cells in Squamous Cell Epithelia Detected by a Mammalian Lectin
}

\author{
J an Plzáka,b Zuzana Holikováa,c,d Karel Smetana, J r.a,c \\ Barbora Dvořánkovác,e J ana Hercogovád Herbert Kaltnerg J an Motlik ${ }^{f}$ \\ Hans-J oachim Gabiusg \\ a Institute of Anatomy, 1st Faculty of Medicine, b Department of Otorhinolaryngology and Head and Neck Surgery, \\ 1st Faculty of Medicine, ' Center for Cell Therapy and Tissue Repair, 2nd Faculty of Medicine, dDepartment of \\ Dermatology, 2nd Faculty of Medicine, and eDepartment of Burn Surgery, 3rd Faculty of Medicine, \\ Charles University, Prague, and fInstitute of Animal Physiology and Genetics, Academy of Sciences of the \\ Czech Republic, Liběchov, Czech Republic, gFaculty of Veterinary Medicine, Institute of Physiological Chemistry, \\ Ludwig Maximilians University, Munich, Germany
}

\section{Key Words}

Carcinoma, basal cell · Cell differentiation · Galectin-3 · Lectin. Squamous epithelia

\begin{abstract}
The squamous stratified epithelia contain a proliferative (harboring mitotic activity) and a differentiating compartment. Due to the potential of protein-carbohydrate interactions to regulate cellular activities we introduced a mammalian lectin to cyto- and histochemical analysis. We answer the questions of whether and to what extent this new probe can pinpoint differentiation-dependent
\end{abstract}

\begin{tabular}{ll}
\hline Abbreviations used in this paper \\
\hline CK10 & cytokeratin type 10 \\
DBA & Dolichos biflorus agglutinin \\
Gal-3 & galectin-3 \\
PBS & phosphate-buffered saline \\
\hline
\end{tabular}

\begin{tabular}{ll}
\hline KARGER & ○ 2002 S. Karger AG, Basel \\
Fax +41613061234 & 1422-6405/02/1713-0135\$18.50/0 \\
$\begin{array}{l}\text { E-Mail karger@karger.ch } \\
\text { www.karger.com }\end{array}$ & $\begin{array}{l}\text { Accessible online at: } \\
\text { www.karger.com/journals/cto }\end{array}$
\end{tabular}

glycosylation changes in sections and in culture of keratinocytes. Material and Methods: Purification and labeling enabled monitoring of galectin-3 reactivity in frozen sections of human and pig epidermis and basal cell carcinomas as well as in culture of keratinocytes. The staining pattern of the lectin was correlated with the staining profile of other cell markers including desmosomal proteins, $\beta_{1}$ integrin, and the proliferation marker Ki-67. The Dolichos biflorus agglutinin (DBA) sharing binding reactivity of galectin-3 to the A type histoblood group epitope was used for comparison. Results: Both lectins exhibit suprabasal binding. However, their profiles were not identical, substantiated by lack of coinhibition. Strong DBA reactivity was also observed in a limited number of basal layer cells, namely in cells without the expression of the proliferation marker Ki-67. Cultured mitotic epidermal cells have no reactivity for DBA. Presence of ligands for this plant lectin was connected with decreased positivity of nuclei for Ki-67 and the occurrence of ring-shaped nucleoli, micronucleoli or absence of nucleoli. Considering colocalization the pattern of galectin-3-binding sites coincided with the presence of desmosomal proteins such as desmoplakin- 1 and desmoglein but not $\beta_{1}$ inte-

\footnotetext{
Dr. Karel Smetana

Institute of Anatomy, 1st Faculty of Medicine

Charles University, U nemocnice 3

CZ-128 00 Prague 2 (Czech Republic)

E-Mail ksmet@lf1.cuni.cz
} 
grin, a potential ligand. Interestingly, studied basal cell carcinomas expressed no binding sites for galectin-3, while a limited number of cells were DBA-reactive. Conclusion: The expression of galectin-3-binding sites and also DBA-reactive glycoligands correlates with an increased level of differentiation and/or cessation of proliferation in the examined squamous stratified epithelia. Further application of tissue lectins for characterizing ligand expression and its modulation is an important step to reveal functional relevance.

Copyright $\odot 2002$ S. Karger AG, Base

\section{Introduction}

Squamous epithelia such as the epidermis represent an example of a morphologically and funtionally diversified tissue. The pool of mitotically active cells is located in the basal layer of the epithelium. It includes the epidermal stem cells and their daughter cells, i.e. the transit-amplifying cells with already limited mitotic ability. The other cell population, the postmitotic differentiating cells, move laterally and superficially. The functional specialization of these cells such as formation of desmosomes and keratinization increases in the course of this process [Cotsarelis et al., 1999; Kaur and Li, 2000]. Differences between cells from basal and suprabasal layers with respect to receptor expression such as integrins and cadherins as well as display of intermediate filaments (cytokeratins) have been considered useful for diagnostic purposes [Watt and Jones, 1993; Hodivala and Watt, 1994; Jensen and Wheelock, 1996; Kanitakis, 1998]. For example, the stem cells differ from other cell types of the basal cell layer in quantity of presence of certain adhesion molecules such as the $\beta_{1}$ integrin chain [Watt, 1998]. It is noteworthy that this integrin subunit bearing $\beta$-galactosides and poly-Nacetyllactosamine extension in its glycan chains is not only involved in protein-protein interactions. In fact, it can be a target for the endogenous lectin galectin-3 (Gal3), a factor in the terminal differentiation of epithelial cells by hensin assembly into large aggregates (Ochieng et al., 1998; André et al., 1999; Hikita et al., 2000]. Thus, in addition to determinants for protein-protein interaction reactants in other systems of molecular recognition deserve consideration in cyto- and histochemical analysis. Oligosaccharides and endogenous lectins establish the ligand-receptor part of information transfer of the sugar code [Reuter and Gabius, 1999; Gabius, 2000; Solís et al., 2001]. In this report we address the questions if and to what extent epitopes reactive with an endogenous lectin in squamous cell epithelia undergo differentiation-dependent changes. So far, classical plant lectin histochemistry has been the standard method to access glycan expression and its modulation. Due to fine-specificity differences between plant and mammalian lectins, even between those harboring identical monosaccharide specificity, as seen for example for galactose [Brinck et al., 1998], it is obvious that monitoring actual capacity for establishing recognitive interactions in situ is advanced by using endogenous lectins as test substances.

Staining of sections from normal skin and skin cancers with carrier-immobilized carbohydrate ligands as well as biochemical analysis has revealed that receptors for galactosides, especially the already mentioned Gal-3, are present [Gabius et al., 1990]. Gal-3 expression was detected predominantly in suprabasal layers of squamous cell epithelia, while its presence is very sparse or lacking in the basal cell layer and in cells of basal cell cancer of skin [Konstantinov et al., 1994; Holíková et al., 1999; Smetana et al., 1999]. Using labeled Gal-3 as probe, highly differentiated cells of squamous cell carcinomas are positive in contrast to cells with a low level of differentiation [Delorge et al., 2000; Plzák et al., 2000]. In this system, galectin-1-binding proved to be less selective [Plzák et al., 2000]. Furthermore, expression patterns of binding sites can vary with cellular activity as seen within tumor cells and during the murine hair cycle [André et al., 1999; Schwarz et al., 1999; Wollina et al., 2000]. These combined findings raise the interest to employ the mammalian galectin as tool to monitor functionally relevant changes in addition to classical plant lectin histochemistry. Concerning functional aspects Gal-3 participates in cell-extracellular matrix and intercellular interactions and in macrophage activation following nonclassical secretion to the extracellular space. It also exerts an antiapoptotic effect and is involved in pre-mRNA splicing [for review, see Gabius, 1997, 2001; Kaltner and Stierstorfer, 1998; Perillo et al., 1998; André et al., 1999; Hughes, 1999; Smetana et al., 1999; Liu, 2000]. Recent studies furthermore point to functional implication in dendritic cells, where the Gal-3 transcript belongs to the set of 78 messages downregulated upon maturation and the protein is found among the set of proteins related to apoptosis in the exosomes [Dietz et al., 2000; Théry et al., 2001].

In this study we thus examine the binding of labeled Gal-3 to human and pig epidermis, human oral mucosa (tongue) and basal cell carcinoma. In addition, we used cultured human epidermal cells. Because the plant lectin Dolichos biflorus agglutinin (DBA) shares binding properties to the trisaccharide of the A type histoblood group 
antigen with Gal-3, we assessed the binding profile of this probe. By double labeling, colocalization of lectin-binding sites with $\beta_{1}$ integrin chain (a potential Gal-3 ligand), intermediate filaments (cytokeratin 10, CK10), desmosomal proteins (desmoplakin-1, desmoglein) and markers of proliferation (Ki-67) was evaluated to infer functional consequences of Gal-3 and DBA binding. With the localization of Gal-3-reactive epitopes in squamous epithelia differentiation under normal as well as pathological conditions we add complementary information to the listed reports on immunohistochemical detection of Gal-3.

\section{Material and Methods}

Preparation of Tissue and Cell Culture Samples

Samples of collected tissue (table 1) were embedded into TissueTek (Sakura-Finetek Europe B.V. Zoeterwoude, The Netherlands), frozen in liquid nitrogen and stored at $-70^{\circ} \mathrm{C}$ prior to further processing. Human epidermal cells were cultured according to a published procedure in a modified version [Green et al., 1979; Dvořánková et al., 1996] on the surface of coverslips for 48 and $216 \mathrm{~h}$ with lethally irradiated 3T3 mouse fibroblasts as feeders. For refined monitoring of properties of proliferating keratinocytes a lesion was deliberately set in 288-hour-old cultures (the cell colonies from the middle of the covered area were manually removed), and the

Table 1. Number of tissue samples

\begin{tabular}{ll}
\hline Tissue & Number of donors \\
\hline Human epidermis (eyelid, chest) & 5 \\
Human oral mucosa (base of tongue) & 3 \\
Pig ${ }^{1}$ epidermis & 1 \\
Basal cell carcinoma & 3 \\
\hline
\end{tabular}

1 Minnesota breed. 'wounded' cultures were then processed for analysis $48 \mathrm{~h}$ later. Triplicates for each time point were evaluated independently.

\section{Tissue and Cell Processing}

The double-labeling procedure with an antibody probe and a second lectin probe was previously described [Froňková et al., 1999; Plzák et al., 2000]. Briefly, 10- $\mu$ m-thin cryostat sections (Cryocut-E, Reichert, Vienna, Austria) and cultured cells covering coverslips were washed with phosphate-buffered saline (PBS) and fixed with $2 \%(\mathrm{w} / \mathrm{v})$ paraformaldehyde for $5 \mathrm{~min}$ at room temperature. All specimens were washed 3 times with PBS, and permeabilized with cold acetone for $5 \mathrm{~min}$. Incubation with a $0.1 \%$ solution of bovine serum albumin (Sigma, Prague, Czech Republic) in PBS was used to block sites for nonspecific protein-protein interaction. Reactive sites were visualized using biotinylated Gal-3 [André et al., 1999; Plzák et al., 2000] or DBA (Vector Laboratories, Burlingame, Calif., USA) as probes, both in a concentration of $20 \mu \mathrm{g} / \mathrm{ml}$ of incubation solution (Tris-buffered saline with $10 \mu \mathrm{M}$ of $\mathrm{CaCl}_{2}$ and an antibody diluted as recommended by the supplier). Lack of influence of the chemical modification on the properties of Gal-3 was ascertained by solidphase assays [André et al., 2000]. Further combinations of lectin and antibody were tested, as summarized in table 2. FITC-labeled swine anti-mouse antibodies (USOL, Prague, Czech Republic) and TRITClabeled ExtrAvidin (Sigma) were used to visualize the immuno- and lectin histochemical reactions. Incubation of lectins with lactose and/ or the label-free neoglycoligand containing the trisaccharide of A histoblood group antigen served as a competitive control to exclude carbohydrate-insensitive binding. Preincubation of specimens with label-free Gal-3 prior to the incubation step with biotinylated DBA was employed to illustrate the extent of overlap of binding of both lectins used. The specificity of immunohistochemical reactions was further tested by the omission of the first-step antibodies or by their replacement with the antibody anti-CD1a (Immunotech, Prague, Czech Republic) in the routine procedure. This antibody recognizes Langerhans cells in the epidermis only. Any binding to other cells would indicate a presence of non-antigen-dependent binding sites for the control monoclonal antibody in the frozen section, a potential for false-positive data also for the antibodies from the test panel. The specimens were mounted with Vectashield (Vector Laboratories, Burlingame) and then examined with a fluorescence microscope (Optiphot-2 equipped with filterblocks for FITC and TRITC fluorescence detection). The picture files were stored and the intensity of the fluorescence signal was quantitated using a computer-assisted image analysis system (LUCIA) with a CCD camera (Cohu; Laboratory Imaging, Prague, Czech Republic).
Table 2. Panel of lectins and antibodies used

\begin{tabular}{lll}
\hline Lectins & Antigens & Source of antibody \\
\hline Gal-3 & CK10 & Dako, Glostrup, Denmark \\
DBA & Ki-67 nuclear antigen of proliferating cells & Immunotech, Prague, Czech Republic \\
& Desmosomal protein desmoplakin-1 & Progen, Heidelberg, Germany \\
& Desmosomal protein desmoglein & Progen, Heidelberg, Germany \\
& $\beta_{1}$ integrin chain & Generous gift of Dr. Fionna \\
& & Watt, Keratinocyte Lab., \\
& & Cancer Research Fund, London, UK
\end{tabular}


Fig. 1. Expression of Gal-3-binding sites (red signal) (A-D) and DBA-binding sites (DBA-BS; red signal) (E-G2) in human epidermis (A, E-G2), human oral mucosa epithelium - tongue $(\mathbf{B}, \mathbf{C})$ and cultured keratinocytes (D). Expression of Ki-67 (A, G1, G2), desmoplakin-1 (Dp-1) (B), desmoglein (Dg) (C), $\beta_{1}$ integrin chain $(\mathbf{D}, \mathbf{E})$ and CK10 (F) leads to the green signal. Colocalization of both signals (red/green) yields yellow color. Arrows indicate position of basement membrane $(\mathbf{A}, \mathbf{F})$. A limited number of basal cells of human epidermis (b) presented binding sites for both DBA and $\beta_{1}$ integrin chain (E). Ki-67-positive nuclei are marked with asterisks $(\mathbf{G 1}, \mathbf{G 2})$. Bar $=10 \mu \mathrm{m}$.
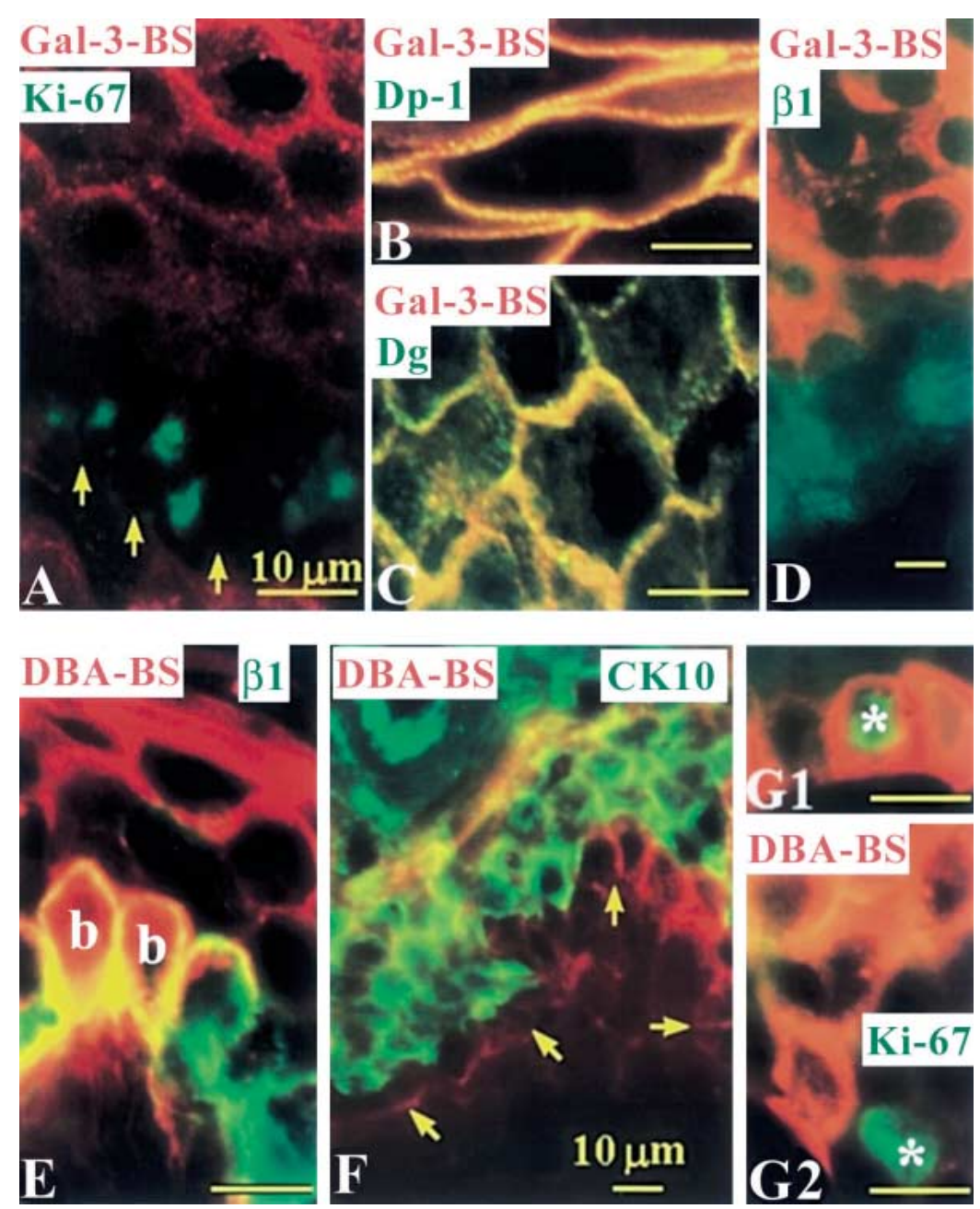

\section{Results}

\section{Normal Epithelia in situ}

Gal-3 was labeled after recombinant expression without influence on its binding properties. The active preparation could thus be introduced to the histochemical part of the investigation as a tool to localize accessible binding sites for a mammalian lectin. Competitive inhibition ascertained the activity of the carbohydrate recognition domain as receptor or as negative modulator of specific protein-protein interactions by Gal-3. Gal-3-reactive sites were expressed suprabasally in human and porcine epidermis, the predominant site of Gal-3 expression, as well as in human oral mucosa. The nuclei of cells binding Gal3 were negative for the presence of Ki-67 in specimens of human origin (fig. 1A). The lack of Gal-3 reactivity in the basal layer is intriguing. Even if secreted from suprabasal cells Gal-3 will not function as effector due to the strict separation of accessible binding sites. In comparison staining profiles, galectin and immunohistochemistry, Gal-3-binding sites showed the same distribution pattern suprabasally as signals for the expression of desmosomal proteins such as desmoplakin-1 and desmoglein in both studied human epithelia (fig. 1B, C, table 3). This observation was corroborated by automatic computer-assisted analysis of the fluorescence intensity profiles (fig. 2, 3). The $\beta_{1}$ integrin subunit as present only in the cells located basally (fig. 1E). However, in this case no colocalization with binding sites for Gal-3 was observed. Cells with Gal3-binding sites shared positivity for CK10 in human and pig epidermis (table 3 ).

The variable but mainly weak signal of DBA binding to the cell surface was observed suprabasally in all studied types of epithelia. The cells of the basal layer of human 


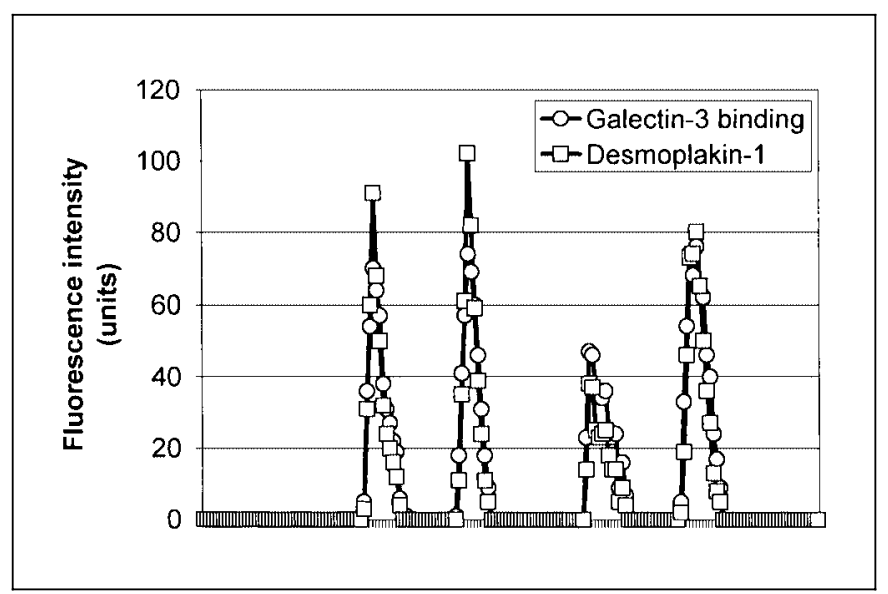

Fig. 2. Fluorescence intensity measured for four representative intercellular contacts at the level of spinous layer of lingual mucosa. Gal3-binding sites and desmoplakin-1 are colocalized.

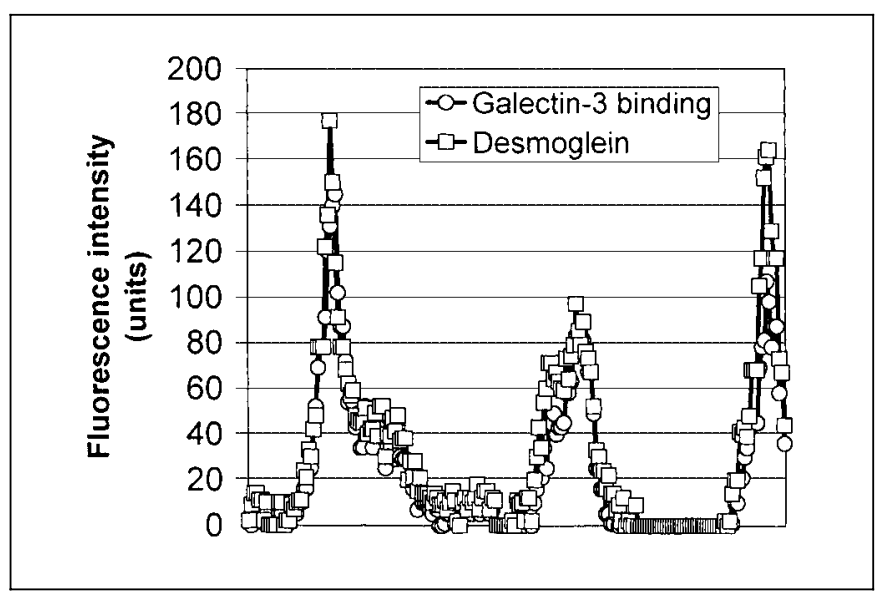

Fig. 3. Fluorescence intensity measured for three representative intercellular contacts are the level of spinous layer of lingual mucosa. Gal-3-binding sites and desmoglein are colocalized.

Table 3. Expression of Gal-3 and DBA-reactive glycoligands and differentiation markers

\begin{tabular}{|c|c|c|c|c|c|c|c|}
\hline Tissue & Gal-3-BS & DBA-BS & Ki-67 & CK10 & $\beta_{1}$ & Dp-1 & $\mathrm{Dg}$ \\
\hline Epidermis (human) & $\begin{array}{l}\text { SBC++ } \\
\text { BC- }\end{array}$ & $\begin{array}{l}\mathrm{SBC}+/++ \\
\mathrm{BC}-/++\end{array}$ & $\begin{array}{l}\text { SBC- } \\
\text { BC-/++ }\end{array}$ & $\begin{array}{l}\text { SBC++ } \\
\text { BC-/+ }\end{array}$ & $\begin{array}{l}\text { SBC- } \\
\mathrm{BC}++\end{array}$ & $\begin{array}{l}\text { SBC++ } \\
\text { BC-/+ }\end{array}$ & $\begin{array}{l}\text { SBC++ } \\
\text { BC-/+ }\end{array}$ \\
\hline Epidermis (pig) & $\begin{array}{l}\mathrm{SBC}++ \\
\mathrm{BC}-\end{array}$ & $\begin{array}{l}\text { SBC+ } \\
\text { BC- }\end{array}$ & ND & ND & ND & ND & ND \\
\hline Mucosa (human) & $\begin{array}{l}\text { SBC++ } \\
\text { BC- }\end{array}$ & $\begin{array}{l}\text { SBC+ } \\
\text { BC- }\end{array}$ & $\begin{array}{l}\text { SBC- } \\
\text { BC-/++ }\end{array}$ & $\begin{array}{l}\text { SBC- } \\
\text { BC- }\end{array}$ & $\begin{array}{l}\text { SBC- } \\
\mathrm{BC}+\end{array}$ & $\begin{array}{l}\mathrm{SBC}++ \\
\mathrm{BC}-/+\end{array}$ & $\begin{array}{l}\mathrm{SBC}++ \\
\mathrm{BC}-/+\end{array}$ \\
\hline Epidermis (cultured) & $-/++$ & $-/++$ & $-/+/++$ & $-/++$ & $-/+$ & ND & ND \\
\hline BC carcinoma & - & $-/++$ & $-/++$ & ND & ++ & $-/++$ & $-/++$ \\
\hline
\end{tabular}

Semiquantitative parameters: - = negative; + = weak positivity; ++ = strong positivity. $\mathrm{BC}=$ Basal layer cells; $\mathrm{SBC}=$ suprabasal cell layer cells; Gal-3-BS = galectin-3-binding sites; DBA-BS = DBA-binding sites; $\beta_{1}=\beta_{1}$ integrin chain; Dp-1 = desmoplakin-1; Dg = desmoglein; ND = not determined.

epidermis (not the pig epidermis and human mucosa) amount to $30-40 \%$ of cells strongly positive on the surface. The signal for the expression of the $\beta_{1}$ integrin chain in these cells was also very intense (fig. 1E). The majority (90\%) of these DBA-positive basal keratinocytes was devoid of $\mathrm{Ki}-67$ presence in the nuclei. A Ki-67-positive nucleus was rarely present in a DBA-reactive basal cell (fig. 1G1). Interestingly, DBA-negative basal cells with Ki-67-positive nuclei were often located in the vicinity of a basal DBA-positive cell. Frequently, a cluster of highly
DBA-positive suprabasal cells was seen in the vicinity of a DBA-negative, Ki-67-positive basal cell (fig. 1G2). Immunohistochemically, a so-called normal epidermis close to basal cell cancer tissue was characterized by conspicuous presence of Ki-67-positive nuclei. The unilateral cytoplasmic binding of DBA close to the Ki-67-positive nucleus was commonly observed (not shown).

DBA-positive basal cells generally revealed no clear indication for the presence of CK10 (fig. 1F). However, the measurements of the fluorescence intensity showed 


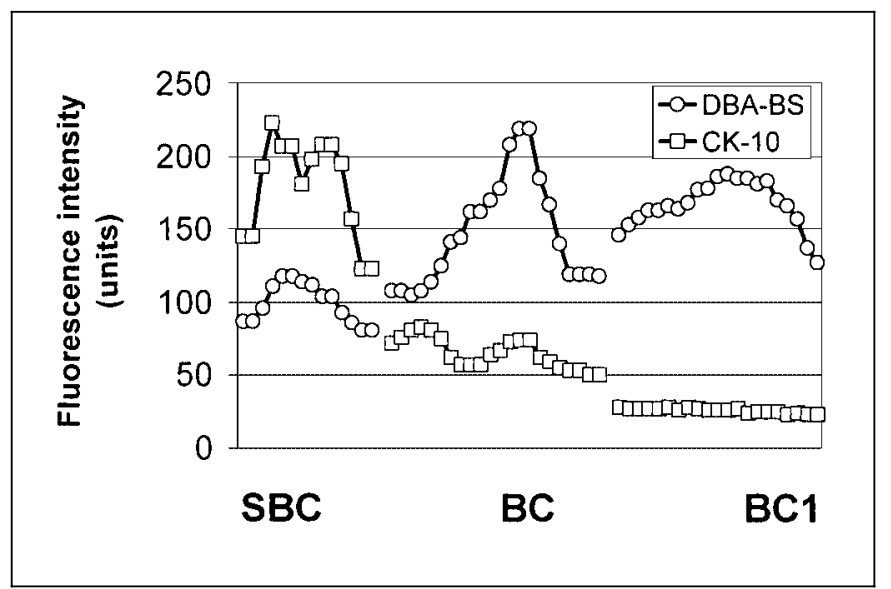

Fig. 4. Measurement of the fluorescence intensity in representative intercellular contacts in suprabasal layer (spinous layer, SBC) and basal layer (BC) of human epidermis for expression of CK10 and binding sites for DBA. Only few basal cell interfaces displayed a wave-like pattern very similar to that of suprabasal layers (SBC). The majority of intercellular contacts revealed no signal for the presence of CK10 (BC1). DBA-BS = DBA-binding sites.

low frequency (up to 10\%) of DBA-positive basal cells expressing a very weak signal for CK10. The DBA-negative basal cells were completely devoid of these intermediate filaments (fig. 4). Basal cell positivity for DBA contrasted with lack of binding of Gal-3. Despite sharing a common aspect within the cellular binding patterns it is evident that the plant (exogenous) and mammalian (endogenous) lectins differed in individual binding properties. To further underscore this conclusion, we performed competition experiments with the two lectins. The preincubation of sections with label-free Gal-3 had no inhibitory effect on the binding of labeled DBA indicating different profiles of glycans for these two lectins (not shown). In order to extend our analysis to tissue culture conditions, we monitored keratinocytes in culture.

\section{Cultured Epidermis}

The Gal-3-binding-site-harboring cultured keratinocytes were negative for the expression of $\beta_{1}$ integrin and Ki-67 (table 3). In small colonies, cells with binding sites for Gal-3 were located in the center of the respective colony surrounded by $\beta_{1}$ integrin-positive keratinocytes (fig. 1D). Up to $20 \%$ of $\beta_{1}$ integrin-positive keratinocytes at the stage of subconfluent or confluent growth were DBA-reactive circumnuclearly (fig. 5A). Because the Golgi complex represents the central site of glycan chain elaboration, this area labeled with DBA could represent places for GalNAc incorporation. To assess cell features after a mechanic stimulus, we removed cells from the culture mimicking a lesion. The 'wounded' cultures reacted by occurrence of proliferating cells, which were devoid of binding capacity for DBA in the mitotic cells (fig. 5B1). Similarly, the cells with highly Ki-67-positive nuclei and compact nucleoli failed to bind DBA (fig. 5B2). The significant decrease of the Ki-67-dependent signal in chromatin and the presence of ring-shaped nucleoli or micronucleoli were connected with cytoplasmic or cell surface binding of DBA in the cultured keratinocytes (fig. 5B3, table 4). Cultured epidermal cells without a Ki-67 signal in the nuclear region were highly positive for the expression of DBA-reactive glycoligands (fig. 5B4). CK10 positivity did not (strictly) correlate with the binding of Gal-3 as well as DBA, because CK10-positive and CK10-negative cells were recognized by both lectins (fig. 5C, table 3).

\section{Basal Cell Carcinoma in situ}

No binding of Gal-3 to tumor cells was observed. Because macrophages as internal positive control reacted with the labeled galectin, a false-negative result due to technical problems could be excluded (fig. 5D). DBA staining of tumor cells had a variable, mosaic-like pattern, and cells reactive with DBA expressed desmoplakin-1, desmoglein and the $\beta_{1}$ integrin chain (fig. 5E). Tumor cells with Ki-67-positive nuclei were characterized by the absence of DBA reactivity (fig. 5F).

\section{Discussion}

Multilayered squamous epithelia are morphologically stratified tissues with stem cells positioned in the basal layer. The phenotype of the basal cell layer differs from that of the suprabasal ones in the expression of several markers such as cytoskeletal proteins, integrins and cadherin receptors. Expression of markers involved in protein-carbohydrate interaction and sugar-code-dependent signaling [Villalobo and Gabius, 1998] can also reveal nonuniform expression. Gal-3 expression with preferential presence suprabasally and its downregulation in basal cell carcinoma is an example pointing to relevance of protein-carbohydrate recognition systems [Konstantinov et al., 1994; Castronovo et al., 1999; Holíková et al., 1999]. We therefore examined whether epitope presentation accessible for Gal-3 is likewise subject to regulation. The study of Gal-3-specific ligand expression in squamous cell carcinomas has demonstrated its occurrence in the mark- 
Fig. 5. Detection of DBA-binding sites (DBA-BS; red signal) (A-C, E, F) and Gal-3-binding sites (red signal) (D) in cultured keratinocytes (A), 'wounded' culture of keratinocytes $(\mathbf{B}, \mathbf{C})$ and basal cell carcinomas (D-F). Expression of $\beta_{1}$ integrin chain $(\mathbf{A}, \mathbf{E})$, Ki-67 (B1-B4, F), CK10 (C) and desmoplakin-1 (Dp-1) (D) leads to the green signal. Colocalization of both signals (red/green) yields yellow color. $\mathrm{N}=$ Nucleus (A, B4). Arrows point to nucleoli (B2, B3). Basal cell carcinoma specimen expressed desmoplakin-1 but not Gal-3-BS in contrast to infiltrating leukocytes that served as internal positive control reaction with the biotinylated galectin (D). Positive blood vessel serves (for DBA-BS) as a control to exclude false negativity $(\mathbf{F})$. Bar $=10 \mu \mathrm{m}$.
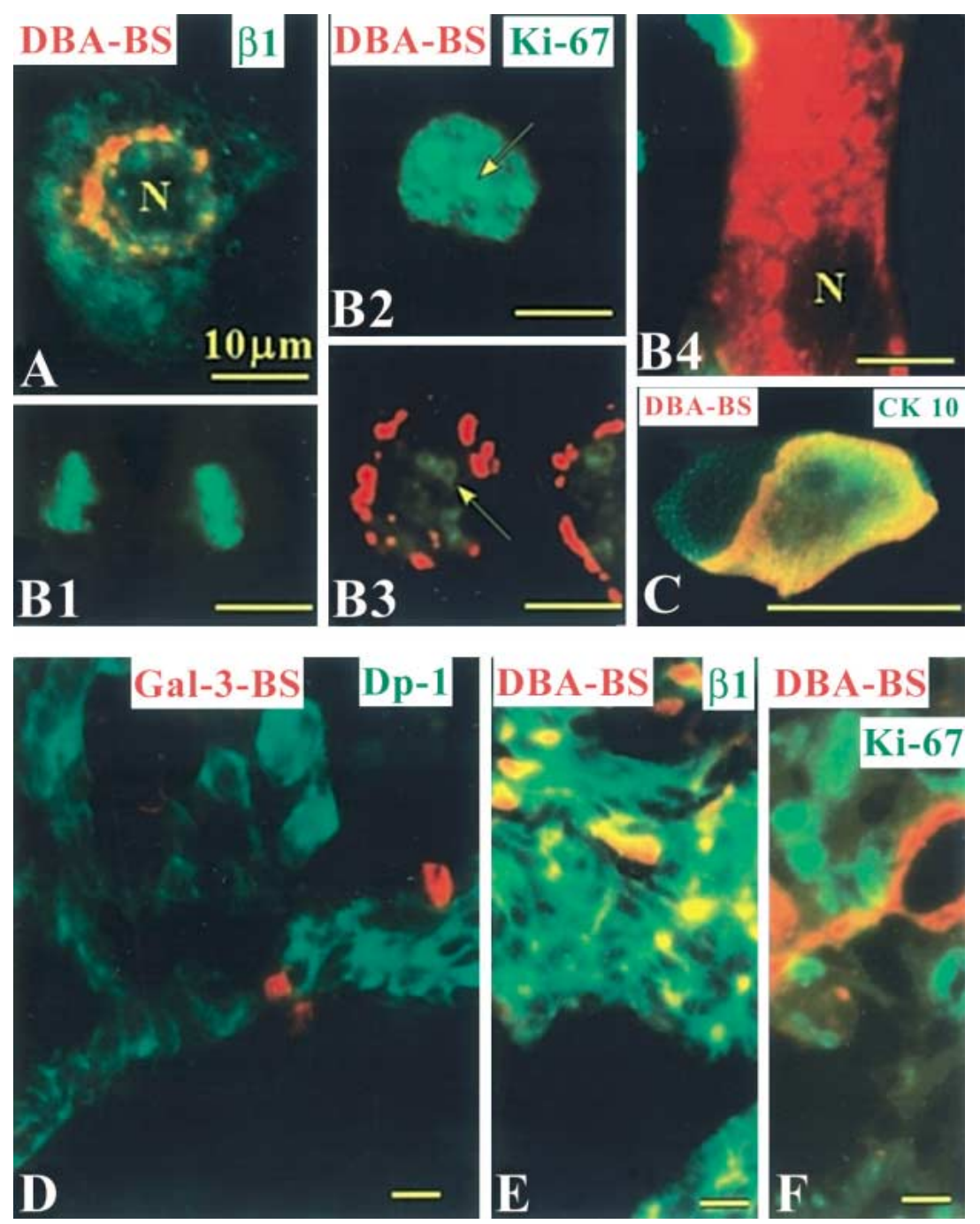

Table 4. DBA binding to cultured keratinocytes and its relation to $\mathrm{Ki}-67$ expression and nucleolar morphology

\begin{tabular}{llll}
\hline Cells & $\begin{array}{l}\text { Chromatin Ki-67 } \\
\text { FI arbitrary units }\end{array}$ & Nucleolus Ki-67 & DBA-BS \\
\hline Mitotic & $\geq 240$ & Not present & - \\
\hline Interphasic & $122 \pm 47$ & Compact & - \\
\cline { 2 - 4 } & $66 \pm 44$ & $\begin{array}{l}\text { Compact (38\%) } \\
\text { Ring-shaped (62\%) }\end{array}$ & Golgi complex \\
\cline { 2 - 4 } & Negative & Micronucleoli (13\%) & Golgi complex \\
\cline { 2 - 4 } & Negative & Micronucleoli (5\%) & Cell surface \\
\hline
\end{tabular}

FI = Fluorescence intensity; DBA-BS = DBA-binding sites. 
edly differentiated parts of carcinomas in contrast to the presence of ligands for galectin-1 in these systems [Delorge et al., 2000; Plzák et al., 2000]. The suprabasal expression of Gal-3-binding sites, observed in the studied human and pig epithelia, corroborates these observations and is suggestive of potential auto- and/or paracrine functions of this galectin. Both studied desmosomal proteins occurred suprabasally and their expression is differentiation-dependent [Kreis and Vale, 1994]. The colocalization between Gal-3-binding sites and desmosomal proteins (desmoplakin, desmoglein-1) supports the notion that these are accessible for Gal-3 at intercellular contacts. The desmosomes constitute heavily glycosylated intercellular contacts [Cohen et al., 1983; Schaumburg-Lever, 1990] and binding of Gal-3 to this region may, therefore, concern these contacts. Due to the tendency of Gal-3 to form multivalent oligomers [Hsu et al., 1992; Ochieng et al., 1993] it is conceivable that this lectin may participate in regulating the strength of intercellular contacts of the suprabasally located cells. The lack of Gal-3 binding to the $\beta_{1}$ integrin chain, a potential ligand via glycan chains, intimates differentiation- or organ-type-specific differences in glycosylation. Alternatively, the relevant epitopes could already be blocked completely in situ by a lectin masking the glycans. As already mentioned in the introduction, this can well be the case for hensin. Gal-3 is efficiently bundling it for deposition in the matrix, a factor for induction of terminal differentiation of epithelial cells [Hikita et al., 2000]. To examine whether a masking occurs, immunohistochemical colocalization of Gal-3 (or other galectins with affinity to $\beta_{1}$ integrin glycans) and the integrin will have to be performed.

In culture, Gal-3-binding cells are negative for $\beta_{1}$ integrin and Ki-67. Both basal cell carcinomas and the basal cell layer possess no accessible ligands for Gal-3. These observations, including previous reported findings in other systems, indicate that the expression of Gal-3 and the population of its ligands is characterized for the pool of nonproliferating cells of squamous cell epithelia. Working with $\mathrm{T}$ cell lymphomas and fibroblasts, an antiapoptotic and proproliferative function of Gal-3 has been detected [Yang et al., 1996; Inohara et al., 1998]. Moreover, Gal-3 blocks the inhibition of proliferation by galectin- 1 in human SK-N-MC neuroblastoma cells [Kopitz et al., 2001]. Our results in squamous epithelia suggest that the role of Gal-3 as proproliferative and antiapoptotic agent might be cell-type-specific for $\mathrm{T}$ lymphocytes, neuroblastoma cells and different studied epithelia, because Gal-3 and Gal-3-reactive sites are expressed in the pool of nonproliferating cells. As shown for cholesteatomas, the pres- ence of Gal-3 could also contribute to prevent progressive apoptotic cell loss upon external stimulation [Sheikholeslam-Zadeh et al., 2001].

Drawing attention to the binding of the core structure in addition to substituted $\beta$-galactosides, it can be explained that the staining profiles with the GalNAc-specific DBA and Gal-3 did not overlap to a notable extent. Evidently, substitution of a $\beta$-galactoside by GalNAc will in this case not produce a frequently encountered set of shared ligands. With respect to binding of this commonly used plant lectin, the expression in the epithelium appears to be species-specific. A weak signal was located on suprabasal cells in all studied epithelia and on a fraction of basal cells in human epidermis, but not in pig epidermis and human mucosa. The positivity of basal cells in epidermis and the signal absence in basal layer of oral mucosa have been observed previously [Kariniemi and Virtanen, 1989; Mizukawa et al., 1994]. Our observation of suprabasally located DBA-positive adds to this body of evidence. The DBA-positive basal cells express $\beta_{1}$-containing integrins and they are usually in the vicinity of DBA-negative basal keratinocytes, which express the Ki-67 antigen. Rarely, some of these DBA-positive basal cells also express CK10, which is usually used as a marker of terminally differentiated cells, and CK10 positivity of terminally differentiating basal cells has been reported [Kaur and Li, 2000].

Another interesting feature of our analysis was circumnuclear binding of DBA. It was detected in few keratinocytes expressing $\beta_{1}$ integrin when cultured to a confluent monolayer. The stimulation of keratinocyte proliferation by the removal of cells from the center of the tissue plate ('wounded culture') influenced the phenotype of cultured keratinocytes concerning DBA binding. No binding of DBA was observed in the mitotic cells showing intense Ki-67 staining. Similarly, the interphasic cells with strongly Ki-67-positive nuclei and prominent Ki-67-positive compact nucleoli were negative for DBA-binding sites. The decrease of $\mathrm{Ki}-67$ expression in nuclei and the conspicuous change of nucleolar morphology from compact to the ring-shaped nucleoli or micronucleoli was connected with circumnuclear expression of DBA-binding sites. These data suggest that the binding of DBA may be related to differentiation of epidermal cells and the loss of their proliferative capacity. The observed changes of the nucleolar morphology strongly support this hypothesis, because compact nucleoli are connected with the production of rRNA, the ring-shaped nucleoli with the reversible arrest of production of rRNA and micronucleoli with an irreversible block of this synthetic line [Busch and Smetana, 1970; Smetana and Broulik, 1994]. In contrast to the 
in situ observation, in vitro experiments showed no relationship between expression of CK10 and that of Gal-3or DBA-binding sites. CK10-positive and CK10-negative cells were recognized by both lectins.

Basal cell carcinoma cells display a phenotype very similar to that present in the basal cell layer of a normal human epidermis. They lack accessible Gal-3-binding sites and a limited number of cells express DBA-binding sites (mosaic-like pattern). The basal layer of the normal epidermis was also negative for the presence of Gal-3reactive glycoligands and only few cells in this section were reactive for DBA.

The glycosylation patterns detected with the endogenous lectin Gal-3 and the plant lectin DBA are a sensitive phenotypic marker of epidermal cell differentiation, encouraging especially further use of endogenous lectins in the analysis of epithelial tissue with cell biological or pathological focus. Due to the presence of more than one type of galectin in various cell types [Gabius et al., 1998; Lahm et al., 2001], further investigations will have to take other family members into account.

\section{Acknowledgments}

This study was supported by the Academy of Sciences and the Czech Republic (Project No. S4050005), the Ministry of Education, Youth and Sport of the Czech Republic (Projects No. MSM 111100005 and No. LN00A065), Grant Agency of the Ministry of Public Health (Project No. ND 6340-3/2000) and the W. SanderStiftung (Munich). The authors are grateful to Eva Vancová for excellent technical assistance.

\section{References}

André, S., B. Frisch, H. Kaltner, D.L. Desouza, F Schuber, H.-J. Gabius (2000) Lectin-mediated drug targeting. Selection of valency, sugar type (Gal/Lac) and spacer length for cluster glycosides as parameters to distinguish ligand binding to C-type asialoglycoprotein receptors and galectins. Pharm Res 17:985-990.

André, S., S. Kojima, N. Yamazaki, C. Fink, H Kaltner, K. Kayser, H.-J. Gabius (1999) Galectins- 1 and -3 and their ligands in tumor biology. J Cancer Res Clin Oncol 125:461-474.

Brinck, U., M. Korabiowska, R. Bosbach, H.-J. Gabius (1998) Detection of inflammation- and neoplasia-associated alterations in human large intestine using plant/invertebrate lectins, galectin-1 and neoglycoproteins. Acta Anat 161: 219-233.

Busch, H., K. Smetana (1970) The Nucleolus. New York, Academic Press.

Castronovo, V., F.-T. Liu, F.A. van den Brule (1999) Decreased expression of galectin-3 in basal cell carcinoma of the skin. Int $\mathrm{J}$ Oncol 15 . 67-70.

Cohen, S.M., G. Gorbsky, M.S. Steiberg (1983) Immunochemical characterization of related families of glycoproteins in desmosomes. J Biol Chem 258: 2621-2627.

Cotsarelis, G., P. Kaur, D. Dhouailly, U. Hengge, J Bickenbach (1999) Epithelial stem cells in the skin: Definition, markers, localization and functions. Exp Dermatol 8: 80-88

Delorge, S., S. Saussez, P. Pelc, B. Devroede, H. Marchant, M. Burchert, F.-Y. Zeng, A. Danguy, I. Salmon, H.-J. Gabius, R. Kiss, S. Hassid (2000) Correlation of galectin-3/galectin-3binding sites with low differentiation status in head and neck squamous cell carcinomas. Otolaryngol Head Neck Surg 122: 834-841.
Dietz, A.B., P.A. Bulur, G.J. Knutson, R. Matasic, S. Vuk-Pavlovic (2000) Maturation of human monocyte-derived dendritic cells studied by microarray hybridization. Biochem Biophys Res Commun 275: 731-738.

Dvořánková, B., K. Smetana Jr., J. Vacík, M. Jelínková (1996) Cultivation of keratinocytes on polyHEMA and their migration after inversion. Folia Biol (Praha) 42: 83-86.

Froňková, V., Z. Holíková, F.-T. Liu, J. Homolka, D.C. Rijken, S. André, N.V. Bovin, K. Smetana Jr., H.-J. Gabius (1999) Simultaneous detection of endogenous lectins and their binding capacity at the single-cell level - A technical note. Folia Biol (Praha) 45: 157-162.

Gabius, H.-J. (1997) Animal lectins. Eur J Biochem 243: $543-576$

Gabius, H.-J. (2000) Biological information transfer beyond the genetic code: The sugar code. Naturwissenschaften 87: 108-121.

Gabius, H.-J. (2001) Glycohistochemistry: The why and how of detection and localization of endogenous lectins. Anat Histol Embryol 30: 3-31.

Gabius, H.-J., M.S. Heil, H. Berger (1990) Glycohistochemistry of endogenous lectins in cutaneous cancer. Anticancer Res 10: 1627-1632.

Gabius, H.-J., C. Unverzagt, K. Kayser (1998) Beyond plant lectin histochemistry: Preparation and application of markers to visualize the cellular capacity for protein-carbohydrate recognition. Biotech Histochem 73: 263-277.

Green, H., O. Kehinde, J. Thomas (1979) Growth of cultured human epidermal cells into multiple epithelia suitable for grafting. Proc Natl Acad Sci USA 76: 5665-5668.

Hikita, C., S. Vijayakumar, J. Takito, H. Erdjument-Bromage, P. Tempst, Q. Al-Awqati (2000) Induction of terminal differentiation of epithelial cells requires polymerization of hensin by galectin-3. J Cell Biol 151: 1235-1246.
Hodivala, K.J., F.M. Watt (1994) Evidence that cadherins play role in the downregulation of integrin expression that occurs during keratinocyte terminal differentiation. J Cell Biol 124 . 589-600.

Holíková, Z., K. Smetana Jr., M. Burchert, B. Dvořánková, R. Klubal, J. Bartůňková, F.-T. Liu, H.-J. Gabius (1999) Expression of galectin-3, galectin-3-binding epitopes and of $\mathrm{Gal} / \mathrm{Gal}-$ NAc-binding sites in keratinocytes of adult human epidermis. Electr J Pathol Histol 5: 9921003.

Hsu, D.K., R.I. Zuberi, F.-T. Liu (1992) Biochemical and biophysical characterization of human recombinant IgE-binding protein, an S-type animal lectin. J Biol Chem 267: 14167-14174.

Hughes, R.C. (1999) Secretion of the galactin family of mammalian carbohydrate-binding proteins. Biochim Biophys Acta 1473: 172-185.

Inohara, H., S. Akahani, A. Raz (1998) Galectin-3 stimulates cell proliferation. Exp Cell Res 245 . 294-302.

Jensen, P.J., M.J. Wheelock (1996) The relationship among adhesion, stratification and differentiation in keratinocytes. Cell Death Differ 3. 357-371.

Kaltner, H., B. Stierstorfer (1998) Animal lectins as cell adhesion molecules. Acta Anat 161: 162179.

Kanitakis, J. (1998) Immunohistochemistry of normal skin. Eur J Dermatol 8: 539-547.

Kariniemi, A.L., I. Virtanen (1989) Dolichos biflorus agglutinin (DBA) reveals a similar basal cell differentiation in normal and psoriatic epidermis. Histochemistry 93: 129-132.

Kaur, P., A. Li (2000) Adhesive properties of human basal epidermal cells: Analysis of keratinocyte stem cells, transit amplifying cells, and postmitotic differentiating cells. J Invest Dermatol 114: 413-420. 
Konstantinov, K.N., B. Shames, G. Izuno, F.-T. Liu (1994) Expression of $\varepsilon B P$, a $\beta$-galactosidebinding soluble lectin, in normal and neoplastic epidermis. Exp Dermatol 3: 9-16.

Kopitz, J., C. von Reitzenstein, S. André, H. Kaltner, J. Uhl, V. Ehemann, M. Cantz, H.-J. Gabius (2001) Negative regulation of neuroblastoma cell growth by carbohydrate-dependent surface binding of galectin-1 and functional divergence from galectin-3. J Biol Chem, in press.

Kreis, T., R. Vale (1994) Guidebook to the Extracellular Matrix and Adhesion Proteins, ed 2. London, Oxford University Press.

Lahm, H., S. André, A. Hoeflich, J.R. Fischer, B. Sordat, H. Kaltner, E. Wolf, H.-J. Gabius (2001) Comprehensive galectin fingerprinting in a panel of 61 human tumor cell lines by RTPCR and its implications for diagnostic and therapeutic procedures. J Cancer Res Clin Oncol 127: 375-386.

Liu, F.-T. (2000) Galectins: A new family of regulators of inflammation. Clin Immunol 97: 7988 .

Mizukawa, Y., K. Takata, Y. Ookusa, M. Nagashima, H. Hirano (1994) Lectin binding pattern in normal labial mucosa. Histochem J 26:863869.

Ochieng, J., M.L. Leite-Browning, P. Warfield (1998) Regulation of cell adhesion to extracellular matrix proteins by galectin-3. Biochem Biophys Res Commun 246: 788-791.

Ochieng, J., D. Platt, L. Tait, V. Hogan, T. Raz, P. Carmi, A. Raz (1993) Structure and function relationship of a recombinant human galactoside-binding protein. Biochemistry 32: 4455 4460.
Perillo, N.L., M.E. Marcus, L.G. Baum (1998) Galectins: Versatile modulators of cell adhesion, cell proliferation, and cell death. J Mol Med 76: 402-412.

Plzák, J., K. Smetana Jr., J. Betka, R. Kodet, H. Kaltner, H.-J. Gabius (2000) Endogenous lectins (galectins- 1 and -3 ) as probes to detect differentiation-dependent alterations in human squamous cell carcinomas of the oropharynx and larynx. Int J Mol Med 5: 369-372.

Reuter, G., H.-J. Gabius (1999) Eukaryotic glycosylation: Whim of nature or multipurpose tool? Cell Mol Life Sci 55: 368-422.

Schaumburg-Lever, G. (1990) Ultrastructural localization of lectin-binding sites in normal skin. J Invest Dermatol 94: 465-470.

Schwarz, G., M. Remmelink, C. Decaestecker, I. Gielen, v. Budel, M. Burchert, F. Darro, A. Danguy, H.-J. Gabius, I. Salmon, R. Kiss (1999) Galectin fingerprinting in tumor diagnosis. Differential expression of galectin-3 and galectin-3-binding sites, but not of galectin-1 in benign versus malignant uterine smooth muscle tumors. Am J Clin Pathol 111: 623-631.

Sheikholeslam-Zadeh, R., C. Decaestecker, C. Delbrouck, A. Danguy, I. Salmon, Y. Zick, H. Kaltner, S. Hassid, H.-J. Gabius, R. Kiss, G. Choufani (2001) The levels of expression of galectin-3, but not of galectin-1 and galectin-8, correlate with apoptosis in human cholesteatomas. Laryngoscope 111: 1042-1047.

Smetana, K. Jr., P. Broulik (1994) Nuclear and nucleolar kinetics in multinucleate osteoclasts in the chick development and after the hormonal treatment. Folia Biol (Praha) 40: 201207.
Smetana, K. Jr., Z. Holíková, R. Klubal, N.V. Bovin, B. Dvořánková, J. Bartůňková, F.-T. Liu, H.-J. Gabius (1999) Coexpression of binding sites for A (B) histo-blood group trisaccharides with galectin-3 and Lag antigen in human Langerhans cells. J Leukoc Biol 66: 644-649.

Solís, D., J. Jiménez-Barbero, H. Kaltner, A. Romero, H.-C. Siebert, C.-W. von der Lieth, H.-J Gabius (2001) Towards defining the role of glacans as hardware in information storage and transfer: Basic principles, experimental approaches and recent progress. Cells Tissue Organs 168: 5-23.

Théry, C., M. Boussac, P. Véron, P. Ricciardi-Castagnoli, G. Raposo, J. Garin, S. Amigorena (2001) Proteomic analysis of dendritic cellderived exosomes: A secreted subcellular compartment distinct from apoptotic vesicles. J Immunol 166: 7309-7318.

Villalobo, A., H.-J. Gabius (1998) Signaling pathways for transduction of the initial message of the glycocode into cellular responses. Acta Anat 161: 110-129.

Watt, F.M. (1998) Epidermal stem cells: Markers, patterning and control of stem cell fate. Philos Trans R Soc Lond B 353: 831-837.

Watt, F.M., P.H. Jones (1993) Expression and function of keratinocyte integrins. Development suppl: 185-192.

Wollinga, U., D. Lange, R. Paus, M. Burchert, H.-J Gabius (2000) Expression of galectin-1 and -3 and of accessible binding sites during murine hair cycle. Histol Histopathol 15: 85-94.

Yang, R.-Y., D.K. Hsu, F.-T. Liu (1996) Expression of galectin-3 modulates T-cell growth and apoptosis. Proc Natl Acad Sci USA 93: 67376742. 